\title{
Emotional Processing of Fear: Exposure to Corrective Information
}

\author{
Edna B. Foa and Michael J. Kozak \\ Temple University
}

\begin{abstract}
In this article we propose mechanisms that govern the processing of emotional information, particularly those involved in fear reduction. Emotions are viewed as represented by information structures in memory, and anxiety is thought to occur when an information structure that serves as program to escape or avoid danger is activated. Emotional processing is defined as the modification of memory structures that underlie emotions. It is argued that some form of exposure to feared situations is common to many psychotherapies for anxiety, and that confrontation with feared objects or situations is an effective treatment. Physiological activation and habituation within and across exposure sessions are cited as indicators of emotional processing, and variables that influence activation and habituation of fear responses are examined. These variables and the indicators are analyzed to yield an account of what information must be integrated for emotional processing of a fear structure. The elements of such a structure are viewed as cognitive representations of the stimulus characteristic of the fear situation, the individual's responses in it, and aspects of its meaning for the individual. Treatment failures are interpreted with respect to the interference of cognitive defenses, autonomic arousal, mood state, and erroneous ideation with reformation of targeted fear structures. Applications of the concepts advanced here to therapeutic practice and to the broader study of psychopathology are discussed.
\end{abstract}

The last two decades have brought remarkable advances in the behavioral treatment of pathological fears and an abundance of data on treatment outcomes. This accumulation of data, however, has not been paralleled by theoretical understanding of the processes that relate interventions to outcome. In this article we examine the data on treatment of fear and offer a framework for organizing them. Within this framework we advance hypotheses about the mechanisms of therapeutic change and consider why treatment succeeds with some individuals and fails with others.

The search for mechanisms of fear reduction can begin with recognition of some commonalities in how different schools of psychotherapy view anxiety and its treatment. Regardless of their theoretical persuasion, clinicians have long ascribed a central role to anxiety or other unpleasant affect in the etiology and maintenance of neurotic behavior. A basic assumption in psychodynamic approaches has been that neuroses reflect attempts to avoid disturbing experiences (Freud, 1956). In describing pathology, Perls (1969) asserted that, "If some of our thoughts, feelings are unacceptable to us, we want to disown them but only at the cost of disowning valuable parts of ourselves. . . . Your ability to cope with the world becomes less and less" ( $p$. 11). Most explicit are the behaviorists who have viewed anxiety

Preparation of this manuscript was supported in part by National Institute of Mental Health Research Grant MH31634 awarded to Edna B. Foa.

Critical reviews of earlier drafts of this manuscript were contributed by Dave Barlow, Bruce Cuthbert, Uriel Foa, Dick Hallam, Peter Lang. Isaac Marks, Richard McNally, Greg Miller, Jackie Persons, and Gail Steketee. Their criticism and suggestions are gratefully acknowledged as are those of the anonymous reviewers and the Editor.

Correspondence concerning this article should be addressed to Edna B. Foa, Department of Psychiatry, Program for the Clinical Study of Anxiety Disorders, Temple University, c/o Eastern Pennsylvania Psychiatric Institute, 3300 Henry Avenue, Philadelphia, Pennsylvania 19129. disorders as continuous attempts to avoid confrontation with fear-evoking cues (Mowrer, 1960).

Despite their theoretical differences, a common principle for the treatment of neuroses has emerged across schools of psychotherapy: the principle of exposure. Indeed, if neurotics are avoiders who fail to recognize and/or retrieve discomfort-evoking information about themselves or their environment, psychotherapy might be construed as providing a setting in which confrontation with such information is promoted so that changes in affect can occur. Psychodynamically oriented therapists expose their patients to information about unconscious conflicts, painful memories, and unacceptable wishes through interpretation of their behavior in therapy, of dreams, or of free associations. Likewise, Gestalt therapists use imagery, role-enactment, dream interpretation, and group-interaction to coax a person into "the here-and-now," that is, to promote confrontation with information that has been avoided. Techniques that more directly promote confrontation with fearful events have been developed by behavior therapists.

A wealth of evidence attests to the efficacy of exposure techniques (for reviews see Foa \& Kozak, 1985; Marks, 1978). They lead to long-term improvement in about $75 \%$ of agoraphobics (Emmelkamp \& Kuipers, 1979) and obsessive-compulsives (Foa et al., 1983); these two disorders had long been considered intractable. In contrast, relaxation treatment with obsessive-compulsives (Marks, Hodgson, \& Rachman, 1975) and long discussions of anxiety symptoms with agoraphobics (Chambless, Foa, Groves, \& Goldstein, 1980) produced little change. Long before this experimental evidence was available, clinical observations had led both Freud (1956, p. 399) and Fenichel (1963, p. 215) to recognize in vivo exposure as a highly potent procedure for treating phobias.

How does exposure help to reduce anxiety? By what mechanisms might emotional change occur? The behaviorist view that anxiety disorders are founded in abnormal associations among 
stimuli and responses has led to explanations of fear reduction in terms of stimulus -response dissociation. However, limitations of contiguity theories in explaining learning phenomena have been widely recognized (e.g., Wagner \& Rescorla, 1972), as have also the difficulties in explaining fear acquisition and maintenance by traditional learning theories (Eysenck, 1976; Rachman, 1976). The argument that the "signal value" of a stimulus is an important predictor of conditioning (e.g., Grings, 1976; Kamin, 1969) has indicated the need for an "informational model" of learning (Reiss, 1980; see also Levey \& Martin, 1983). This view seems to imply that in addition to formed associations, some aspects of the meaning of the associated events are involved in learning. Thus, satisfactory explanations of fear and its reduction may require attention not only to stimulus-response associations, but also to their meanings.

In the present article we try to explicate how exposure leads to fear reduction. We adopt the position that fear is represented in memory structures that serve as blueprints for fear behavior, and therapy is a process by which these structures are modified. We argue that two conditions are required to reduce pathological fear: First, the fear structure must be activated, and next, information incompatible with its pathological elements must be incorporated. It follows that understanding the therapeutic process involves the identification of information that promotes fearactivation and that modifies the fear structure. This identification, in turn, requires theoretical unraveling of the fear structure. Toward this end, a model of pathological fears is discussed and a pathway for their correction via treatment proposed. ${ }^{1}$

\section{Fear and its Modification}

\section{Structure of Fear Memory}

A starting point for considering the mechanisms of exposure therapies can be found in Lang's (1977, 1979) bioinformational conceptualization of fear, which is couched in terms of the "propositional representation" position (Anderson \& Bower, 1974; Kieras, 1978; Pylyshyn, 1973) on the nature of cognition. Accordingly, all knowledge can be expressed in an abstract code representing concepts; cognitions are construed as propositional entities and propositions are understood to be logical relations that express concepts. This view is contrasted with some other positions, such as that fundamental differences between visual and verbal cues are involved in cognitions (Paivio, 1971), or that word and sentence meanings are "pictures" themselves (Bugelski, 1970). Although theoretical controversy about the propositional position flourishes (Kosslyn, 1980), and the empirical work of Lang and his associates is not directed specifically at its resolution, the bioinformational theory has led to fruitful investigation of fear.

Adopting Pylyshyn's (1973) construal of a propositional network as an organization of concepts related to one another by other concepts, Lang $(1977,1979)$ suggested an analysis of the fear structure into propositions. Accordingly, fear is represented as a network in memory that includes three kinds of information: (a) information about the feared stimulus situation; (b) information about verbal, physiological, and overt behavioral responses; and (c) interpretive information about the meaning of the stimulus and response elements of the structure. This information structure is conceived of as a program for escape or avoidance behavior.

If the fear structure is indeed a program to escape danger, we propose that it must involve information that stimuli and/or responses are dangerous, as well as information about physiological activity preparatory for escape. Thus, a fear structure is distinguished from other information structures not only by response elements but also by certain meaning or information it contains. For example, the programs for running ahead of a baton-carrying competitor in a race and for running ahead of a club-carrying assailant on a racetrack are likely to involve similar stimulus and response information. That which distinguishes the fear structure is the meaning of the stimuli and responses: Only the fear structure involves escape from threat.

It is apparent that most people experience fear in some circumstances. What then distinguishes the structures of normal fears from those of pathological fears? We suggest that pathological structures involve excessive response elements (e.g., avoidance, physiological activity, etc.) and resistance to modification. The persistence of fears may stem not only from their marked structural coherence (as noted by Lang, 1977) but also from impairments in mechanisms for the processing of fear-relevant information (Foa \& Kozak, 1985).

As a hypothetical construct, a fear structure must be investigated through converging measures. In trying to account for physiological responses measured during fear, Lang (1979) suggested that fear is accompanied by physiological activity determined by the response structure that underlies it. Accordingly, physiological responses measured during fear evocation can provide an index of the fear structure. These responses are thought to reflect prototypes of overt behavior, that is, the much attenuated versions of ordinary actions reflect stored perceptual-motor schemata for those actions. According to this view, an evoked memory structure is influenced by the structure of the fearevoking material. Like memory structures, evocative material (e.g., feared situations or their descriptions) can also be analyzed with respect to its stimulus, response, and meaning elements. Furthermore, the propositional structure of an evoked memory is assumed to parallel the structure of the material that evokes it. Physiological activity recorded during fear evocation, as well as the self-reports of fear, are taken as measures of hypothesized memory structures. Relations of these measures to one another and to input variables can then be evaluated, where input variables are events hypothesized to evoke the structure. Thus, the propositional structure of the evoked memory is hypothesized to depend in part on the structure of evocative material and to be reflected in measurable physiological efferents and self-reports.

Our position certainly does not imply that a fear structure is entirely available to consciousness. Although certain aspects may be identified through introspection, ample evidence (cf. Van Den Berg \& Eelen, 1985) suggests that associations among stimuli, responses, and their meanings can exist in the absence of conscious knowledge about them. Just as a person may be unaware of some response information in a fear structure (e.g., information that underlies increased blood pressure), so also may one

\footnotetext{
I The development of normal and pathological fear memory structures will not be discussed in this article.
} 
be unaware of the meaning of those responses. This is not to say that people are always unaware of meanings associated with stimuli and responses, for they can indeed report beliefs and evaluations that reflect elements in their fear structures. Because of people's imperfect knowledge about their fear structures, nonintrospective assessment of these structures is also required. In addition to recorded physiology, nonverbal behavior such as facial expressions, postural adjustments, overt actions, and so on would also be expected to reflect some elements. Any of these data can provide a basis for hypotheses about the elements of a fear structure and the relations among them.

In the last decade, the assessment of clinical anxiety has been influenced by Lang's (1968) proposal that anxiety involves three systems: physiological activity, subjective report, and overt behavior. Accordingly, fear activation will be reflected in physiological responses measurable at the periphery, in reports about experience of fear, and/or in overt acts such as avoidance or escape. Fear activation, however, does not always give rise to reports of fear or to escape itself. Because we construe a fear structure as a program to escape or avoid, it follows that activation of fear cannot occur without preparatory changes in physiological activity. In this article we focus on physiological indices of fear and to a lesser extent, subjective reports; little attention is given to overt behavioral measures. This emphasis stems mainly from the kind of data available in studies of the process of fear reduction during therapy. Data on overt behavior are more likely to appear as treatment-outcome measures. Thus, a hypothesized structure can be validated via multisystem assessment in a variety of ways. For example, one can provide information thought to match the network and observe whether the responses evoked support the construct.

\section{Modifying an Affective Memory: Emotional Processing}

We propose that regardless of the type of therapeutic intervention selected, two conditions are required for the reduction of fear. First, fear-relevant information must be made available in a manner that will activate the fear memory. Indeed, as suggested by Lang (1977), if the fear structure remains in storage but unaccessed, it will not be available for modification. Next, information made available must include elements that are incompatible with some of those that exist in the fear structure, so that a new memory can be formed. This new information, which is at once cognitive and affective, has to be integrated into the evoked information structure for an emotional change to occur.

The hypothesized change in the fear structure can be conceptualized as the mechanism for what Rachman (1980) has defined as emotional processing: a process by which emotional responses decrease. In contrast to this definition, our view that emotional processing involves incorporation of new information into an existing structure allows for either increased or decreased emotional responding. Indeed, exposure to information consistent with a fear memory would be expected to strengthen the fear. Emotional processing occurs spontaneously throughout life: Emotional responses increase and decrease with experience. Behavioral treatments are designed to provide information that is sufficiently incompatible with the fear structure to reduce fear. Because this article is concerned primarily with processes un- derlying fear reduction, our use of the term emotional processing refers mostly to changes that result in fear decrement.

\section{Indicators of Emotional Processing}

To assess whether emotional processing is complete following therapy, Rachman (1980) suggested the use of "test probes," that is, presentations of relevant stimulus material in an attempt to evoke an emotional reaction. For Rachman, if a fear response is elicited, it indicates that emotional processing has not been successfully completed; conversely, if the probe fails to elicit fear, emotional processing is assumed to have taken place. The testprobe approach to the assessment of emotional processing poses some problems. Whereas evoked fear evidences incomplete emotional processing, the opposite is not necessarily true: Exposure to fear-relevant information does not always activate an existing fear structure (e.g., Chambless et al., 1980; Grossberg \& Wilson, 1968). Therefore, failure to evoke fear with a test probe does not itself indicate that emotional processing has occurred. Rather, it may reflect the inadequacy of the probe material or an avoidance of the information presented. This problem with psychometric reliability limits the validity of the test-probe approach. In addition, assessing emotional processing solely by response to posttreatment test probes may fetter this concept in tautological subservience to treatment outcome.

We surmount these difficulties by identifying indicators of emotional processing (during therapy) that predict therapy outcome and at the same time are logically independent of it. Our solution rests on a distinction between emotional processing and treatment outcome. Emotional processing of fear is a hypothetical construct referring to the ongoing course of change in a fear structure. To measure this course, behavior that directly reflects the structure should be assessed at several points during therapy. The choice of measures depends on how the fear structure is conceptualized. Our view that physiological response information is coded in the structure dictates the use of physiological measures in addition to self-report for assessing emotional processing.

Treatment outcome is distinguished from emotional processing in two ways. First, outcome involves an endpoint at which structural changes are assumed to have occurred, and its measures are designed to assess the new structure. Second, whereas emotional processing of fear is indicated only by measures of that fear, treatment outcome is a broader concept. It also includes functioning indirectly related to the fear structure that is hypothesized to change as a result of fear reduction, such as, job performance, social interactions, sleep disturbance, and general mood state. In summary, the logical distinction between emotional processing and outcome pivots on the ideas of temporal continuity and breadth of measurement. Processing is ongoing, requiring repeated measurement of fear; outcome is discrete, requiring measurement at some endpoint of behavior both directly and indirectly related to the fear structure.

Data collected in various clinical studies reveal a set of responses occurring in patients who improve with exposure treatment, and thus they may serve as indicators of emotional processing. First, these patients give physiological responses and reports of fear that evidence activation of fear during exposure. Second, their reactions decrease gradually (habituate) within ex- 
posure sessions. ${ }^{2}$ Third, initial reactions to the feared object at each exposure session decrease across sessions. Various lines of evidence from both clinical outcome studies and laboratory experiments point to the validity of these indicators.

The first indicator is activation. Lang, Melamed, and Hart (1970) and Borkovec and Sides (1979) found that phobic subjects who profited most from systematic desensitization (gradual exposure to feared images) showed increased heart rates during the initial feared images; weak reactors benefited less from treatment. Similarly, physiological responsiveness during flooding (exposure to situations or images that evoke intense fear) was found to be positively related to outcome of treatment with specific phobics and agoraphobics (Watson \& Marks, 1971).

The second indicator is habituation within sessions. Decreases in cardiac activity have generally been observed during repeated presentations of feared material (e.g., Anderson \& Borkovec, 1980; Borkovec \& Sides, 1979; May, 1977). Investigating changes in reported anxiety during imaginal flooding with obsessivecompulsives and agoraphobics, Foa and Chambless (1978) found that once fear was activated, self-reported anxiety decreased within sessions in a roughly linear fashion. This pattern approximated habituation patterns found during exposure to actual feared situations for heart rate (Grayson, Foa, \& Steketee,1982; Stern \& Marks, 1973; Watson, Gaind, \& Marks, 1972) and for self-reported anxiety (Hafner \& Marks, 1976; Nunes \& Marks, 1975; Stern \& Marks, 1973). Simple phobics who improved with treatment showed greater heart rate habituation during imagery of fearful material than their less successful counterparts (Borkovec \& Sides, 1979; Lang et al., 1970; Watson et al., 1972). Similarly, habituation of reported anxiety during both in vivo and imaginal exposure has been found to predict outcome for obsessive-compulsives (Foa et al., 1983).

The third indicator is decrease in initial reactions to feared stimuli (across-sessions habituation). This has been observed during treatment by exposure even though increasingly difficult situations were added in the course of treatment (Foa \& Chambless, 1978; Grayson et al., 1982; Hafner \& Marks, 1976; Shahar \& Marks, 1980). Habituation across sessions has also been found related to treatment outcome (Foa et al., 1983). Examples of habituation within and across sessions are given in Figure 1.

These data provide diverse support for the proposed indicants of emotional processing. The activation of affect, its reduction during exposure sessions, and its decrease across sessions, appear positively related to treatment outcome, denoting evocation and modification of fear memories during therapy. Conversely, deviations from this pattern may signify that the fear structure has been unavailable for modification or that components of a preexisting memory have not been modified by new information.

The tactic offered here for the assessment of emotional processing requires sufficient repeated measures to establish whether the pattern observed during fear reduction in a given individual corresponds to the hypothesized pattern. With too few data points, one cannot distinguish between lack of fear evocation and habituation when fear responses are not observed. A different method of distinguishing between lack of evocation and fear reduction was employed by Levin (1982), who measured fear-relevant as well as specific fear-irrelevant physiological responses related to the imagined situation. The presence of the specific fear-irrelevant responses was taken to indicate that the fear structure had been accessed, whereas the disappearance of fear responses indicated degree of habituation. Thus, the indicant of memory accessing was logically independent of the indicant of fear.

We have proposed that emotional processing of pathological fear requires the activation of the fear structure and then, the incorporation of corrective information. We have also proposed three indicators of emotional processing: fear responses (indicating that the structure has been accessed), short-term (withinsessions) habituation, and long-term (across-sessions) habituation. All three indicators have been related to treatment efficacy. Accordingly, conditions that enhance fear evocation and habituation are expected to improve treatment outcome. Such conditions are examined in the next section.

\section{Variables That Influence Accessing and Modification of Affective Memory}

\section{Content of the Evocative Information}

A fear memory is accessed when a fearful individual is presented with fear information that matches some of the information structure in memory (Lang, 1977). This information may be about the feared situation, the person's responses in the situation, or their meaning. Lang (1977) suggested that some critical number of information units must be matched for the entire fear memory to be activated, and that some information elements may be especially important in evoking the fear structure. Intense phobias, he proposed, may be characterized by strongly coherent structures that can be evoked with minimally matching information. For example, the sight of a coiled garden hose may elicit intense fear in a snake phobic; a warm sensation may evoke a panic attack in the agoraphobic who fears physiological sensations of anxiety.

Invoking a matching explanation to account for fear activation risks circularity in the absence of other ways to assess the structure. To obviate such circularity one must first identify the structure from self-reports, behavioral observations, and so on. Data about responding to matched information can then be used to validate hypotheses about the structure. Accordingly, situations that vary in their degree of similarity to the hypothesized structure would elicit varying degrees of fear.

In studying variables that influence the accessing of fear structures, Lang and his associates trained subjects to form fearful fantasies through practice with scripts that included descriptions of either a stimulus context only (e.g., a green snake on a rock), or of both a stimulus and specific physiological responses (e.g., your heart pounds). Subjects who had received the training involving responses and who were later tested with scripts containing response descriptions showed greater physiological ac-

\footnotetext{
${ }^{2}$ Habituation has often been used to denote a short-term sensory effect, whereas extinction usually refers to the longer term unlearning of a contingency. This distinction is controversial in the light of the findings that habituation is retained over time (e.g., Groves \& Lynch, 1972). Our use of the term habituation refers simply to response decrement. This is consistent with the Thompson and Spencer (1966) usage of the term: "given that a particular stimulus elicits a response, repeated applications of the stimulus result in decreased response (habituation)" (p. 18).
} 
tivity and reported higher fear than subjects trained and tested with stimulus descriptions only (Lang, Kozak, Miller, Levin, \& McLean, 1980). This finding can be interpreted to indicate that scripts that include response references enhance accessing of a fear structure, but only in conjunction with prior response training.

In another experiment (Lang, Levin, Miller, \& Kozak, 1983), snake and socially anxious subjects received either response training or stimulus training. When later presented with both fear-relevant and fear-irrelevant image scripts, those who had been trained to focus on responses showed increased physiological responding, especially during fear-relevant images. These results seem to indicate that greater matching of input information with a preexisting fear memory enhances fear evocation. Training subjects to focus on responses may have helped them to attend to response elements in the scripts, thus enhancing the match between input information and stored information, thereby calling up the structure more fully. Similarly, the larger responses to fear-relevant scripts were hypothesized to reflect a better match of response scripts with a fear structure than that between re- sponse scripts and a nonfear structure (Lang et al., 1983). In summary, it appears that promoting focus on response information (which corresponds to that in the fear structure) increases the likelihood of fear evocation.

Individuals differ in their responsiveness to imagery training. Miller et al. (1981) found that, prior to training, good and bad imagers did not differ with respect to their physiological responses during fear imagery. After training, only the good imagers showed increased physiological responding. In other studies, with phobic populations, good imagers showed greater physiological responding to fear-relevant scripts than did poor imagers, even when no imagery training was administered (Levin, 1982; Levin, Cook, \& Lang, 1982). Thus, good imagers, if phobic, do not seem to need training to respond to phobic material. These findings suggest individual differences in the ability to use fear-relevant information to access a fear memory. Such a preexisting capacity may influence emotional processing during exposure.

How does the information content of exposure influence fear modification? Little attention has been devoted to analyzing the content of the information presented during exposure sessions.
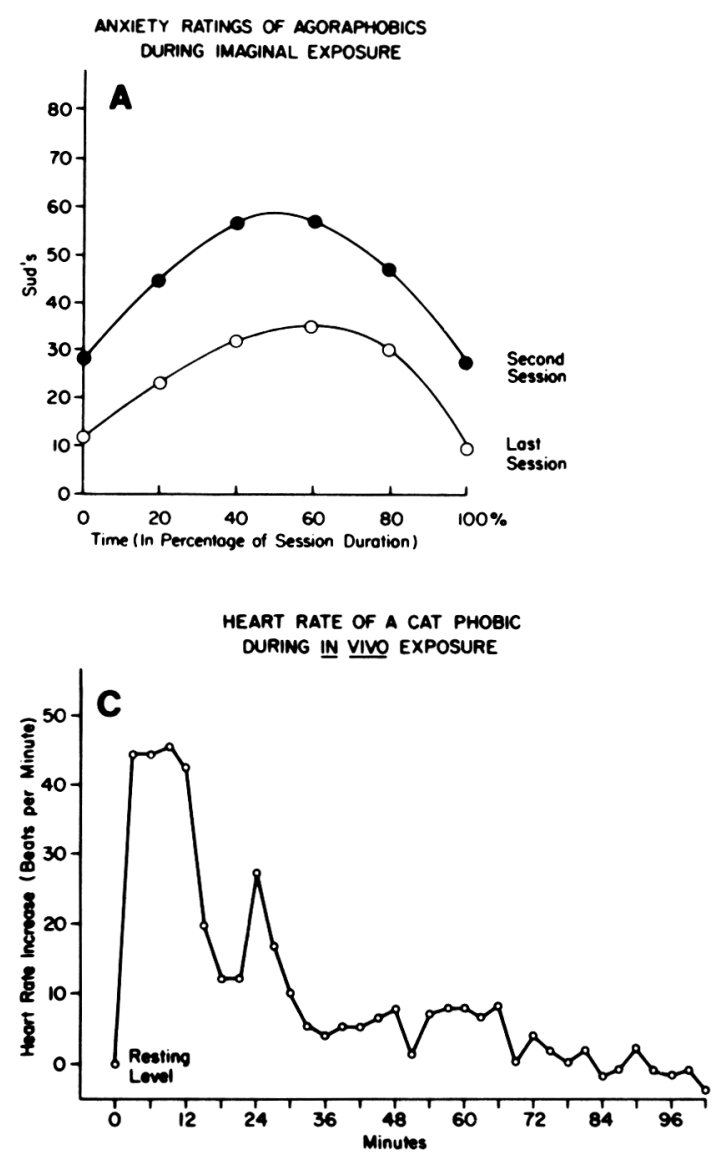

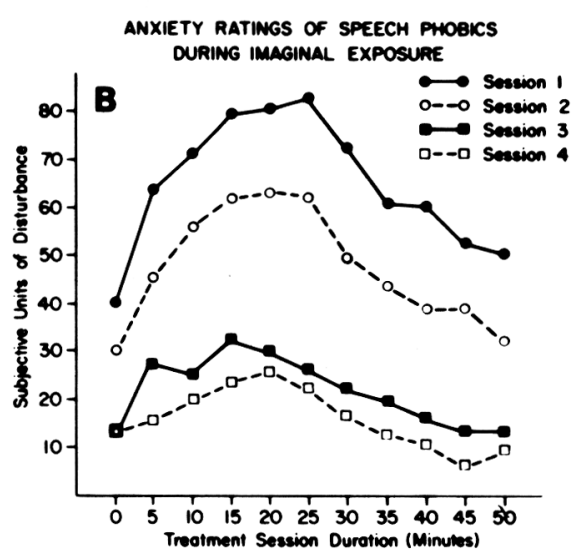

HEART RATE AND ANXIETY RATING

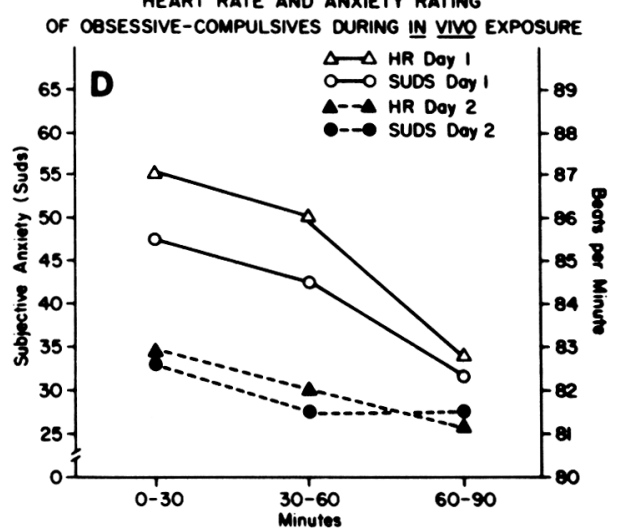

Figure 1. Data from several experiments on habituation during exposure. A: Mean values for six agoraphobics treated with eight 90-min sessions of imaginal flooding (from Foa \& Chambless, 1978). B: Mean values for 24 speech phobic volunteers treated with four 50 -min sessions of imaginal flooding (from Chaplin \& Levine, 1980). C: Data for a single cat phobic during one session of in vivo exposure (from Watson et al., 1972). D: Means for 16 obsessive-compulsives during in vivo exposure to contaminants (from Grayson et al., 1982). (These data illustrate habituation of autonomic and self-report indices of fear and suggest congruence of habituation patterns across measures and procedures.) 
Our framework suggests that increasing the match between the content of exposure situations and that of the fear structure would promote evocation, thereby allowing greater emotional processing and leading to superior therapy outcome. Experimental results bearing on this hypothesis were reported by Foa, Steketee, Turner, and Fischer (1980) with obsessive-compulsives who had checking rituals. In addition to their concrete feared situations to which they were exposed in vivo, all had intense fears of future disasters, which could only be presented in imagination. Half of the subjects received $2 \mathrm{hr}$ of in vivo exposure only. The remaining subjects were instructed to imagine their feared consequences for $90 \mathrm{~min}$ and were then given $30-\mathrm{min}$ exposure in vivo to the feared situation. Thus the total exposure time was the same for both groups. Because disaster scenarios constitute a central component of checkers' fears, but of course are not realized during in vivo exposure, the information delivered in vivo did not constitute such a good match for their fear structures. In vivo exposure alone would thus be expected to produce less improvement than the combined treatment. Contrary to this expectation, both groups improved significantly and no group differences emerged immediately after treatment. However, the group that received both imaginal and in vivo exposure maintained its gains whereas some relapse was evident for those who received in vivo exposure only. Notably, at follow-up the variance in the relapsing group was larger: Some patients did not relapse at all whereas others showed complete relapse. Perhaps those who did not need imaginal exposure to maintain their gains were able to use the limited information presented in vivo to call up other relevant elements in the structure, that is, disaster scenarios. Conversely, when in vivo presentation failed to access these elements, emotional processing was impeded and fear returned.

\section{Evocative Medium}

An obvious way to access a fear memory is confrontation with an actual feared situation. ${ }^{3}$ However, in vivo exposure is not the sole mode of information input that activates fear. Evocative information can be delivered via a variety of audio or visual media. Verbal descriptions, visual displays, or lifelike enactments can contain the required information to access an existing fear structure. Indeed, novels, films, plays, and so on can evoke a range of emotions when the information they contain provides a good match with some affective memory structure in the audience.

Experimental evidence for the effectiveness of different media in activating memory structures comes from investigations of both nonemotional and emotional structures. It has been demonstrated for speech and arm flexion (Jacobson, 1930), weight lifting (Shaw, 1940), and eye tracking (Weerts, 1973), that peripheral physiological activity recorded during in vivo performance of these tasks resembles activity recorded during their imaginal recall. Barber and Hahn (1964) found attenuated patterns of physiological responding during imaginal recall of a coldpressor task that were similar to those found during the task itself. Craig (1968) reported similarity among patterns of heart rate acceleration during an in vivo cold-pressor task and during subsequent imagining of that task. However, Craig also noted some differences across evocative media: (a) Cardiac deceleration (rather than the acceleration found for the in vivo test) was re- corded during observation of a modeled cold-pressor task, and (b) less electrodermal activity occurred during imaginal recall than during the actual cold-pressor task. With nonphobic subjects, McLean (1981) found patterns of cardiac acceleration during images to fearful scripts resembling patterns found during dramatic enactments of feared situations, although the responses evoked by the scripts were weaker. Comparing images evoked by scripts and live enactments of fearful situations, Kozak (1982) found that both media evoked similar physiological activity if subjects had previously received training to focus on physiological responding.

These findings support the claim that information that evokes a fear structure may be transmitted via a variety of media. However, the relative efficacy of a particular medium in activating fear may depend on how well it can depict the elements of the fear structure, as well as on a person's willingness or ability to engage in the recall process. For example, actual (in vivo) presentation of a feared situation is more likely to evoke a fear response than imaginal exposure for simple phobics. Indeed, Watson et al. (1972) found that for simple phobics the average initial heart rate response during fear-relevant images was 8 beats/ min, whereas the average response during in vivo exposure to these same stimuli was 28 beats/min. This difference between the two media was obtained even though in vivo presentation followed exposure in fantasy, during which habituation had already occurred. With obsessive-compulsives, however, in vivo exposure does not seem to be superior in evoking fear. Equivalent increases in self-report and autonomic measures of fear were found for both imaginal and in vivo exposure with ritualizers (Boulougouris, 1977). Because the situations feared by agoraphobics are not readily amenable to in vivo realization in the laboratory, interpretable data about their imaginal versus in vivo responding is unavailable.

Several factors may mediate this difference between obsessivecompulsives and phobics. Obsessive-compulsives may be better imagers than phobics, as available data suggest that good imagers show greater heart rate response to fear scripts than do poor imagers (Levin et al., 1982). Another possible explanation lies in the greater complexity of obsessive-compulsives' fear structures. As discussed earlier, phobics seem to be characterized by strongly coherent fear structures so that even a minimal match can evoke their structures. Foa and Kozak (1985) suggested that obsessive-compulsives may have less coherent structures, necessitating a greater match with the information presented. Exposure in vivo, they proposed, may facilitate intake, but it poses more restrictions than does imaginal exposure on the closeness of the match with the fear structure. Therefore, patients with simple,

\footnotetext{
${ }^{3}$ Whereas avoidance of fear-relevant information prevents amelioration of anxiety, mere confrontation to the feared situation may be neither a necessary nor sufficient condition for fear reduction (DeSilva \& Rachman, 1982). Although, as we argued above, exposure-based treatments are generally most effective in ameliorating fear, we are reminded by DeSilva and Rachman that fear reduction is sometimes observed following verbal persuasion, cognitive therapy, traditional psychotherapy, or administration of placebo. It is difficult to interpret the extent to which these techniques may succeed because they effectively access pathological fear networks, or alternatively, may reduce only "normal" fears that need not be accessed in their entirety for change.
} 
more coherent structures may respond more to in vivo exposure that promotes intake. For patients with complex and less coherent fear structures, the greater flexibility of imaginal exposure may compensate for the superiority of in vivo exposure on other dimensions.

If the evocation of a fear structure can be accomplished by a variety of media, it follows that its modification, that is, emotional processing, and the subsequent clinical improvement could also be achieved via different media. Indeed, much research shows that therapeutic changes in fearful individuals take place following different exposure procedures. With phobic children, live and filmed modeling of peers interacting calmly with feared objects produced equivalent gains (Bandura, Grusec, \& Menlove, 1967). College students who feared snakes reported less fear and increased approach behavior after having imagined other people engaging in contact with snakes (Kazdin, 1973, 1974a, 1974b). Fear reduction has also been observed following cognitive rehearsal (Hart, 1966) and, as noted earlier, deliberate in vivo exposure to feared situations has been repeatedly shown to be therapeutic.

As indicated above, for simple phobics in vivo exposure to feared situations may access a fear structure better than will imaginal procedures, but for obsessive-compulsives, the two procedures seemed equivalent. One would thus expect that for phobics, in vivo treatment would produce greater emotional processing and superior clinical outcomes, whereas for obsessivecompulsives, imaginal and in vivo treatment would produce similar changes. The available data support this prediction. For fearful volunteers, the superiority of in vivo exposure has been demonstrated (Bandura, Blanchard, \& Ritter, 1969; Barlow, Leitenberg, Agras, \& Wincze, 1969; Dyckman \& Cowan, 1978; LoPiccolo, 1969; Sherman, 1972). This is also true for simple phobic patients (e.g., Mathews, 1978). With obsessive-compulsives, both media produce similar outcomes (Foa, Steketee, \& Grayson, 1985; Rabavilas, Boulougouris, \& Stefanis, 1976). The picture is unclear with agoraphobics: Two studies indicate the superiority of in vivo exposure (Emmelkamp \& Wessels, 1975; Stern \& Marks, 1973) and two studies show equivalent gains from imaginal and in vivo treatments (Chambless, Foa, Groves, \& Goldstein, 1982; Mathews et al., 1976).

In summary, the complex results of studies comparing media effects preclude a conclusion of the clear superiority of one medium of exposure for evoking and modifying fear. Rather, the efficacy of a particular medium varies across disorders. As suggested above, this interaction may reflect the adequacy of different media for depicting the information required to match the structures of different types of fear.

\section{Duration of Exposure}

Physiological activity during imagined exposure often follows a curvilinear pattern for heart rate (Mathews \& Shaw, 1973; Ornstein \& Carr, 1975) and for skin conductance (Mathews \& Shaw, 1973; McCutcheon \& Adams, 1975). Responses gradually increase, reach a plateau, and then gradually decrease. During both imaginal and in vivo exposure similar patterns of self-reported fear have also been observed. Foa and Chambless (1978) found that during 90-min exposure sessions with agoraphobics and obsessive-compulsives, self-reported anxiety first increased, leveled off, and then began to decrease after $50 \mathrm{~min}$. A similar pattern was reported by Chaplin and Levine (1980) with speechanxious volunteers, but only with long, continuous exposure. Subjects received 50 min of either continuous imaginal exposure to feared situations or interrupted exposure with a 10-min interval separating two 25 -min exposures. The pattern of gradual increase in self-reported fear followed by a decrease after $25 \mathrm{~min}$ was observed for the long exposure condition only. In contrast, during the shorter exposures reported anxiety increased continuously. In addition, long exposures appeared to produce more across-sessions reduction of reported fear. Similar results were reported for agoraphobics by Stern and Marks (1973), who compared the effects of a $2-\mathrm{hr}$ session of in vivo exposure to those of four 30-min segments separated by 30 -min intervals. Both heart rate and self-reported anxiety were monitored throughout treatment. In the continuous exposure condition, little heart rate reduction was observed until after $1 \mathrm{hr}$. Therefore, patients in the interrupted condition (30-min segments) probably did not have sufficient time for heart rate habituation to occur.

If prolonged exposure results in increased habituation, which indicates more complete emotional processing, it should yield therapy outcomes superior to those achieved with short exposure. This was indeed found in a large number of experiments with animals and humans, including those of Chaplin and Levine (1980) and Stern and Marks (1973; see Marks, 1978, for a review). Additional results attesting to the superiority of prolonged exposure in the clinical setting were reported by Rabavilas, Boulougouris, and Stefanis (1976) for obsessive-compulsives. A prolonged in vivo exposure $(80 \mathrm{~min}$ ) yielded better outcome than eight short exposures $(10 \mathrm{~min}$ ) interrupted by 10 -min intervals.

Notably, the length of exposure required for habituation differs across disorders. Chaplin and Levine's speech phobics started to habituate to fear imagery after $25 \mathrm{~min}$ whereas the agoraphobics in the Foa and Chambless (1978) study began to habituate after $50 \mathrm{~min}$. During in vivo exposure with agoraphobics heart rate decreases after $60 \mathrm{~min}$ were observed (Stern \& Marks, 1973), whereas with specific phobics decreases after about 20 min were found (Watson et al., 1972). It is reasonable to view the fears of agoraphobics as generally more pervasive, intense, and complex than those of simple phobics. Thus, it appears that the more intense or pervasive the fear, the longer the exposure time required to achieve habituation within sessions and the consequent change in the fear structure.

\section{Degree of Attention}

Having considered variables that influence accessing and modification of a fear structure, such as the medium and the message of the exposure, we do not want to neglect what is perhaps an obvious prerequisite for emotional processing: sensory encoding of the information presented. The extent to which such information is encoded can be manipulated by instructions.

Investigating the process of desensitization, Borkovec and Sides (1979) presented speech phobics with fear-relevant images with or without instructions to relax. Relaxed subjects benefited more from treatment by exposure than did nonrelaxed ones. They also reported greater imagery vividness, showed larger initial heart rate responses during imagery, and evidenced more habituation over both identical and hierarchical presentations. The authors 
suggested that these seemingly diverse effects become coherent if relaxation is seen to enhance attention to fear-relevant information. Indeed, if a relaxed subject is better able to encode the available information, he would be expected to access his fear structure more fully; habituation to the fear content can then take place and emotional processing should occur.

The effect of attention during exposure therapy was investigated directly by Grayson et al. (1982). In a crossover design, obsessive-compulsives with cleaning rituals received either exposure with distraction on one day, followed by exposure with attention on the next day, or exposure with attention followed by exposure with distraction. In the distraction session, patients held a contaminant (an anxiety-evoking object) while playing a video game. In the attention sessions, they shared with the therapist their thoughts and feelings about holding the contaminant. Gradual within-sessions decreases in self-reported anxiety and in heart rate were found in both attention and distraction conditions. However, on the second day, fear remained reduced only in patients who had been encouraged to focus attention on the feared stimuli; fear returned in those who had been distracted. Thus, attention facilitated between-sessions, but not within-sessions habituation.

Similar results were obtained by Sartory, Rachman, and Grey (1982) using a different paradigm and a different population: animal-phobic volunteers. All subjects received $20 \mathrm{~min}$ of exposure to their feared object. Half of the subjects were then instructed to think about the object for $30 \mathrm{~min}$ and the other half were asked to distract themselves by reading magazines. Immediately after treatment, the groups did not differ in reported anxiety; partial return of reported fear emerged 1 week later for the distraction group only. Here again, increased attention influenced long-term, but not short-term habituation.

\section{Mechanisms for the Emotional Processing of Fear}

We have adopted the view that fear is evoked by information that activates an existing fear structure containing propositions about stimuli, responses, and their meaning. Changes in such a structure, we have proposed, require the integration of information that is incompatible with some elements of the fear structure. Because exposure therapy promotes lasting fear reduction, it follows that structural change, that is, learning, has occurred. Considerable attention has been devoted to what kinds of processes operate on informational representations to effect structural changes, and several alternative theories, based on associative network models, have been proposed (e.g., Anderson, 1976; Anderson \& Bower, 1973; Hayes-Roth, 1977; Kintsch, 1972). Whereas these theories have focused on the basic learning processes by which structures change, our discussion of mechanisms focuses on what specific informational representations must be changed (i.e., what needs to be learned) for fear reduction to occur. In this section we describe how exposure therapies provide the information that is needed for such change.

\section{Dissociation of Responses From Stimulus Situations}

As we pointed out earlier, situations that evoke large fear reactions cease to do so after repeated or prolonged exposures. It is not within the scope of this article to examine the physiological mechanisms underlying habituation to repeated or prolonged stimulation (cf. Tighe \& Leaton, 1976; Watts, 1979). We propose, however, that regardless of its physiological mechanism, the process of short-term (within-sessions) habituation constitutes information that changes a fear structure. When physiological responses decrease during confrontation with feared situations, interoceptive information about the absence of physiological arousal is generated. This information is available for encoding as response propositions that are inconsistent with those of the structure, thereby weakening the preexisting links between stimulus and response elements. The resultant less "unitized" configuration of elements is less readily evoked by information that matches only some of the elements in the structure.

Systematic desensitization is interpretable as an attempt to create conditions whereby information about the feared stimuli is encoded in the absence of fear responses. Toward this end, relaxation practice during repeated imagery is used. In flooding, prolonging the presentation of fear-evoking information allows the desired response decreases to occur spontaneously. Weakening the links between stimulus and response elements need not always be automatic; it sometimes can involve conscious processes. This is suggested by the results of an experiment on information feedback and fearful avoidance (Sorgatz \& Frumm, 1978). Subjects who were told that decreases in arousal lead to successful treatment benefited more from false feedback indicating that they were relaxed than from false feedback indicating that they were highly aroused.

\section{Meaning of Stimuli and Responses: Implication of Threat}

In addition to promoting changes in the response structure of a fear memory via short-term physiological habituation, clinical observations suggest that confrontation with a feared situation changes its meaning. In other words, propositions about threat that are linked to stimulus and response elements of the fear structure are also modified. Such changes involve a reduction in the exaggerated probability associated with the feared harm and/or a change in the representation of its valence.

The process of weakening associations among propositions about threat and stimulus and/or response elements of a fear structure includes a change in the representations of the probability of the feared consequences (cf. Kahneman \& Tversky, 1982). For example, a dog phobic's repeated exposure to dogs without being bitten incorporates information that the probability of being injured by a dog is quite low; this information will replace certain erroneous representations in the fear structure about the likelihood of threat. Likewise, an obsessive-compulsive who checks the kitchen stove, harboring an image of massive destruction from exploding gas, needs to experience his ability to turn off the gas on the first try.

It is clear from these examples that new information about the probability of harm associated with stimuli affects the fear structure. With respect to harm associated with responses, clinical observations suggest that two kinds of information may require modification. First, many patients report their beliefs that anxiety responses and their attendant discomfort, once initiated, will persist indefinitely. This threat of eternal anxiety, which prompts avoidance, requires disconfirmation. Second, many patients 
(especially agoraphobics) often report their belief that anxiety itself will produce some disaster such as insanity or cardiac arrest. For them, the proposition that persistent anxiety is dangerous must be disconfirmed.

It follows that, in addition to modifying stimulus-response links in the fear structure, short-term (within-sessions) habituation sets the stage for changes in representations of threat regarding the fear responses. Thus, the patient integrates the information that the feared situation constitutes no real danger from without, as well as information that anxiety reactions are of finite intensity and duration. The gradual reduction in both physiological reactions and subjective discomfort in the fear context is itself information incongruent with the proposition that anxiety decreases only through escape or avoidance. Variants of the concept that exposure to a feared situation increases anxiety to some disaster point are also contradicted when habituation occurs during a session of prolonged, uninterrupted exposure.

Even when within-sessions habituation occurs, modifying certain response elements and their associated interpretive meanings, erroneous representations of potential harm from without can persist. If a fear structure is indeed a program to react to threat, fear responses will continue as long as any representation of threat remains. It follows that long-term fear reduction requires weakening the links between stimulus representations of feared situations and associated representations of threat. Often, the potential injury is not expected to occur immediately, as in the case of a germ phobic who anxiously awaits future symptoms from some latent infection. Information that can disconfirm such errors necessarily involves a time delay. Repeated exposures over time allow a new representation of long-term consequences to replace elements of the preexisting fear memory.

Another aspect of meaning is the valence associated with stimulus and response elements of the fear structure. For example, an academician who dreads questioning about his theory does not overestimate the probability of being questioned, but does exaggerate the "badness" associated with such questioning. Repeated exposure to questioning certainly does not indicate that questioning is unlikely, so how does it reduce fear? We propose that the representation of valence (i.e., how good or bad it is to be questioned) is altered via short-term habituation. The reduction of discomfort that accompanies habituation during questioning constitutes information that is incompatible with the existing representation of valence, thereby weakening the association with its stimulus and response elements. If the unpleasantness of being questioned passes quickly, then being questioned is not so bad. Of course exposure to information about another person's values that are incompatible with those represented in the structure can also influence valence.

In short, we have proposed that several types of meanings characterize the fear structures of those who manifest anxiety disorders. First, there is the concept that anxiety will persist until escape is realized. Secondly, the fear stimuli and/or the fear responses are associated with unrealistically high probability for causing either psychological (e.g., going crazy, losing control) or physical (e.g., cardiac arrest, sickness) harm. Thirdly, the threat has an extremely high negative valence for the individual. The first meaning element is corrected via short-term habituation. Correction of elements reflecting inaccurate probabilities of eventual harm often requires repeated exposures; such changes are reflected in long-term habituation. Valence can change through habituation or through exposure to incompatible values.

Results congruent with our proposal that the fear structures of anxious patients involve exaggerated probabilities and valence have been reported by Butler and Mathews (1983), who hypothesized that highly anxious patients will overestimate "subjective personal risk." Questionnaires developed to assess subjective cost and probability of threatening events were administered to anxious patients, depressives, and normal controls. Both patient groups overestimated probabilities and cost compared with normals. Moreover, they were more likely to interpret ambiguous situations as threatening.

Preliminary data about the relation between cognitive representations of threat and treatment outcome were collected from obsessive-compulsives in our clinic at Temple University. A selfreport questionnaire assessing beliefs about response-related (internal) and stimulus-related (external) threat was administered to obsessive-compulsives before and after treatment by exposure and response prevention. Decreases in estimates of internal threat (but not external threat) were significantly correlated with assessors' ratings of improvement in compulsive behavior $(r=.85)$, in urges to ritualize $(r=.55)$, and in obsessive ideation $(r=.43)$. Although these results themselves do not imply a causal relation, they are consistent with our hypotheses and encourage further exploration of the relation among exposure to corrective information about threat, patients' estimates of danger, and outcome of therapy.

In citing the self-report data above as evidence for changes in stimulus-response associations and associated meaning elements, we do not imply that all the cognitive processes discussed in this article would be available to introspection. As noted by Nisbett and Wilson (1977), cognitive processes are not always amenable to accurate assessment via self-report. Consistent with this notion are the findings that only in a minority of instances did phobics report thoughts of negative consequences during imagery of feared situations (Rimm, Janda, Lancaster, Nahl, \& Dittmar, 1977). Because some meaning information may be unavailable to introspection, it may not always be identifiable through discussion with the patient. In fact, available therapy techniques that rely heavily on discussion of self-reported cognitive processes seem to have limited effectiveness with anxiety disorders (for a review, see Foa \& Kozak, 1985).

Emotional processing might be viewed as a sequence of changes in an information structure of which certain elements are unavailable to introspection. Nevertheless, such unconscious changes may influence conscious beliefs and attitudes that traditionally have been viewed as more closely related to overt actions. For example, habituation of autonomic nervous system responses in the presence of a feared stimulus may lead to reduced estimates about the persistance of anxiety, and in turn, to a change in the attitude that "anxiety should be avoided at all cost." This process may promote more general changes in perception of selfefficacy and in behavior itself.

\section{Habituation and Information Processing}

We have suggested that both within-sessions and across-sessions habituation are indicators of emotional processing. Foa (1979) 
has noted that obsessive-compulsives who failed to habituate within sessions also failed to habituate across sessions, suggesting that the two processes are not independent: Long-term habituation must be preceded by short-term habituation. We have argued that repeated contact with a feared situation is required to disconfirm certain erroneous concepts of long-term harm, and that this disconfirmation underlies long-term habituation. Perhaps, in the absence of within-session habituation, the persistent high levels of arousal during exposure interfere with encoding and integration of disconfirming information. Indeed, the interference of high arousal with task performance is documented early in the experimental literature (e.g., Yerkes \& Dodson, 1908).

The proposition that within-sessions habituation enhances integration of corrective information and thereby promotes acrosssessions habituation coincides with the results of experiments on attention that were described earlier (Grayson et al., 1982; Sartory et al., 1982). Despite procedural differences, both experiments yielded similar findings: degree of attention influenced long-term, but not short-term, habituation. Both attention and distraction conditions included presentation of a feared object, which activated the fear structure so that short-term habituation could occur. In the distraction condition, however, fear-irrelevant information (video displays, magazine articles) may have replaced (at least partly) the fear context for the subjects. Thus, relevant available corrective information was not incorporated. In other words, although the feared object was available, information about it was not fully encoded and the formation of a new memory of the feared event was inhibited. In the attention conditions, available stimulus-information was associated with new interoceptive information to weaken the fear structure. It is this new memory that is evoked on subsequent presentations of the feared object.

In summary, we propose that once a fear memory has been evoked by information that matches it, several mechanisms come into play. The information that short-term physiological habituation has occurred leads to dissociation of response elements from stimulus elements of the fear structure. The consequent lowered arousal in turn facilitates integration of corrective information about the meaning of the feared stimuli and responses. Representations of lower potential harm and decreased negative valence obviate the disposition to avoid, thus reducing the associated preparatory physiology: across-sessions habituation occurs. Long-term decreases in anxiety constitute additional information that accumulates to modify general beliefs and attitudes about ability to cope with feared situations. Such changes in global beliefs have been found closely related to behavioral changes (Bandura, 1977). The sequence in which these changes occur may vary somewhat for different disorders and is readily subject to empirical investigation. A schematic illustration of a fear network before and after emotional processing is shown in Figure 2.

The proposed scenario maintains that within-sessions habituation can be relatively independent of higher order cognitive processes, whereas longer term habituation reflects changes in patients' representations of threat. Interestingly, the infra-human literature implicates the brain-stem reticular formation in shortterm habituation and cortical structures in long-term habituation (Groves \& Lynch, 1972).

\section{Failures of Emotional Processing}

We have reviewed evidence that exposure procedures produce long-term decline of anxiety and have tried to explain this effect. However, not all who suffer from excessive fear benefit from repeated exposure (cf. Foa \& Emmelkamp, 1983). Who are the treatment failures and why do they fail to respond? Our account suggests two reasons for the persistence of anxiety. First, the information encoded during exposure may fail to activate the fear structure sufficiently. Second, this information may not be sufficiently incompatible with erroneous elements of the structure, and thus may fail to disconfirm the erroneous concepts.

A failure to activate fear may result from a large discrepancy between the preexisting fear memory and the information embedded in the exposure situation. Even when the situation matches the structure, failure to encode (e.g., cognitive avoidance, inattention) would interfere with fear activation. The inhibitory effects of cognitive avoidance (or motivated inattentiveness) on fear evocation have been described by Borkovec and Grayson
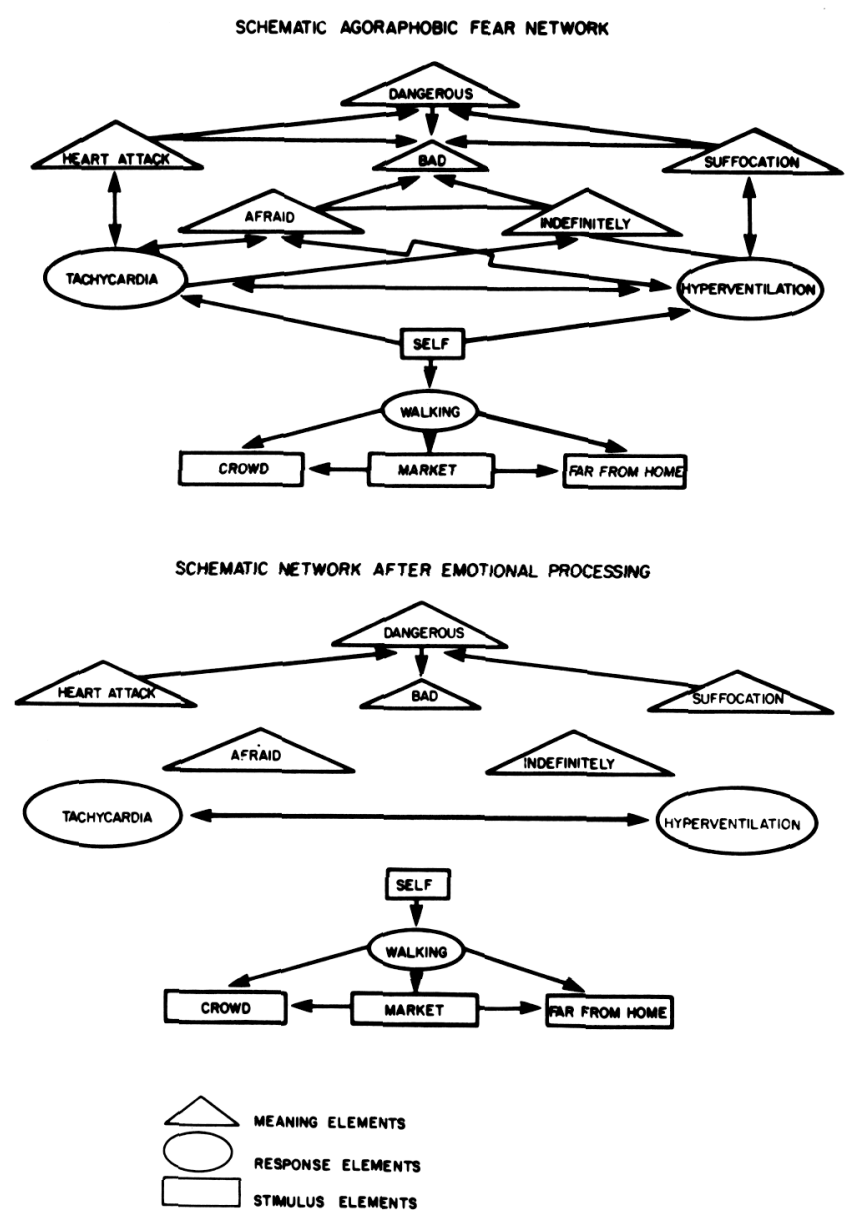

Figure 2. Fear network before and after emotional processing, illustrating that successful therapy disintegrates this fear structure into three clusters of stimulus, response, and meaning elements. (Connecting vectors suggest directions for the various conceptual relations among the elements; e.g., tachycardia causes heart attack, heart attack brings tachycardia, self is walking in the market.) 
(1980) as the absence of "functional exposure." These authors suggested that ". . . objective presentation of stimuli does not guarantee functional exposure to those stimuli. . . . events which interfere with or facilitate the subject's awareness and/or processing of that information [about the feared stimuli] will critically influence the effect of those procedures on the targeted emotional behavior" (p. 118).

In the absence of short-term habituation during exposure, information that is incompatible with stimulus-response links of the fear structure is unavailable. In addition, therapy fails when the available information about potential harm associated with the situation does not contradict erroneous meaning-elements in the fear structure. If a dog phobic were viciously mauled by a dog during an exposure session so that the anticipated catastrophe was realized, sensitization rather than fear reduction would be expected. Because neurotic fears are by definition unrealistic, such realizations rarely occur. More common is the case in which disconfirming evidence is available but does not modify cognitive representations of threat and consequently, habituation across sessions does not occur (cf. Foa \& Kozak, 1985).

Four patient characteristics have been found related to treatment ineffectiveness. Each can be interpreted as a failure to modify a fear structure either because the structure was not accessed or disconfirming information was unavailable.

\section{Cognitive Avoidance}

Observation of patients during exposure provides many examples of cognitive avoidance. Distraction strategies such as pretending to be somewhere else, distorting a fearful image, concentrating on nonfeared elements of a situation, and so on diminish encoding of fear-relevant information and thus impede activation of fear. Concentrating on nonfearful elements of a situation is a common pattern, such as the agoraphobic who focuses on window displays in a shopping mall to avoid attending to the physiological concomitants of anxiety. Less common are distortions of fearful images. An illustrative example of distortion is the cognitive avoidance practiced by a patient who felt contaminated by urine. During exposure sessions urine was put on several places on his arm. A strong initial fear reaction was manifested in nervous movements, blushing, and a very high anxiety rating. However, unlike the gradual reduction of anxiety observed in most patients, a sharp response decrement (within 3-5 min) was observed with this patient. This pattern of high initial response followed by rapid decline was repeated daily: Long-term habituation was not evident. Inquiry revealed a curious avoidance techrique: In his imagination this patient first "froze" the contaminated spots to prevent their "spread"; having controlled them he stopped attending to them. In this case, the observed response decrease seemed not to reflect therapeutic emotional processing but rather, successful avoidance of the contaminant. Despite repeated presentations of potentially corrective information, emotional processing did not occur because the patient reformed potentially incompatible information ("urine is spread but I am not harmed") into compatible information ("urine is contained and I am not harmed"). When the "freezing" maneuver was circumvented, the expected gradual reduction of reported anxiety was observed.

\section{Absence of Short-Term Habituation}

If short-term habituation changes the fear structure by dissociating certain response elements and by generating information about anxiety decreases, patients who fail to habituate during exposure would be expected to profit little from therapy. High tonic arousal (measured by heart rate, skin conductance level, and spontaneous fluctuations) seems to impede short-term habituation. Lader and Wing (1966) reported that complex phobics (agoraphobics, social phobics, anxiety neurotics) showed greater skin conductance responding to neutral stimuli and less habituation of these responses than did simple phobics. The latter, in turn, were more aroused and habituated more slowly to tones than did normals. Interestingly, Lader, Gelder, and Marks (1967) found that patients who habituated to tones benefited more from systematic desensitization than did nonhabituators. These results led Lader and Matthews (1968) to hypothesize a critical level of arousal above which responses to a repetitive stimulus would not habituate.

Unlike arousal, high initial response to fear-relevant information was found to be positively related to cardiac decreases during imaginal desensitization of snake phobics (Lang et al., 1970). Using self-ratings, however, Foa et al. (1983) found a negative, albeit small correlation $(r=-.38)$ between initial reports of anxiety in a feared situation and decreases in these ratings. The observation that high-intensity stimuli hinder habituation in animals (Davis \& Wagner, 1969; Groves \& Thompson, 1970) as well as in humans (Grayson, 1982; O'Gorman \& Jamieson, 1975) appear consistent with the Foa et al. findings.

Indirect evidence that processing of disturbing events is optimal with moderate reactivity comes from Gur et al. (1981), who measured metabolic activity in the frontocortical region of the brain (which has been implicated in the regulation of anxiety and other negative affect) in subjects undergoing an unpleasant medical procedure. Plotting it against state-anxiety scores on the Spielberger State-Trait Inventory, they found a curvilinear relation: Metabolic rates in the frontocortical regions of the brain increased with anxiety to a point above which greater anxiety was associated with decreased metabolic activity. This pattern was not observed in other regions not implicated in anxiety regulation. If metabolic rate is taken as an indicator of the amount of information processed, Gur et al.'s findings suggest that both high- and low-anxious individuals process anxiety-related information less completely than do those who are moderately aroused.

Investigators have attempted to manipulate arousal level with relaxation (e.g., Benjamin, Marks, \& Huson, 1972) and with psychotropic drugs, (see Marks, 1978, for a review). The picture emerging from these studies is unclear: some indicated the enhancement of treatment outcome by high arousal, some by medium arousal, and others by low arousal. Moreover, some studies found arousal level unrelated to treatment outcome. Interpreting these findings is difficult because level of arousal during homework exposure assignments was uncontrolled and because comparative data on arousal levels during treatment across studies is unavailable. Furthermore, the role of arousal level seems to vary for different disorders. For example, in agoraphobia, a disorder that involves fear of arousal itself, presence of arousal dur- 
ing exposure was found to enhance emotional processing (Chambless, Fao, Groves, \& Goldstein, 1982), perhaps because it increased the match between the feared situation and the agoraphobic fear structure.

\section{Depression}

Severe depression has been found associated with unresponsiveness to exposure treatment for both agoraphobics (Zitrin, Klein, \& Woerner, 1980) and obsessive-compulsives (Foa et al., 1983). Conversely, the reduction of depression (with clomipramine) potentiated the action of behavioral treatment with obsessive-compulsives (Marks, Stern, Mawson, Cobb, \& McDonald, 1980). The proposed account of emotional processing suggests several hypotheses for the interference of depression with the effects-exposure treatment.

Various results point to a relation between depression and a diminished capacity for habituation of anxiety that, in turn, is expected to hinder emotional processing during exposure therapy. Depressed obsessive-compulsives have been found to report smaller anxiety decreases both within and across sessions and to improve less with treatment than did their nondepressed counterparts (Foa et al., 1983). A mixed view emerges from the psychophysiological literature on electrodermal responding, with some investigators finding diminished reactivity with depression (Greenfield, Katz, Alexander, \& Roessler, 1963) and others reporting increased responsiveness (Lewinsohn, Lobits, \& Wilson, 1973) and slower habituation (Gatchel \& Proctor, 1976). Perhaps some resolution can be found in Lader and Wing's $(1966,1969)$ findings that retarded and agitated depressives react differently. The agitated depressives were more aroused, and habituated more slowly to tones than normals, whereas the retarded group showed almost no electrodermal activity. Clinical observations suggest that anxiety-disordered patients, when depressed, are more likely to be agitated and may have an associated impairment in habituation, such that they benefit less than nondepressives from exposure treatment.

We propose that the absence of habituation in depressed individuals interferes with emotional processing because: (a) the interoceptive information provided by habituation is unavailable and (b) integration of any available corrective information is impeded by excessive arousal. Other aspects of depressive symptoms also mitigate fear reduction. It has been found, for example, that depressed patients exhibit learning deficits consequent to self-perceptions of ineffectiveness or helplessness (Bandura, 1977; Seligman, 1975). To the extent that emotional processing depends on higher order integration of new fear-relevant information, the learning deficits that characterize depression may mediate the failure of emotional processing. Moreover, the tendency for depressed individuals to attribute successes to external sources and failures to themselves (Abramson, Seligman, \& Teasdale, 1978) may obstruct the development of general beliefs about ability to cope with fear.

\section{Overvalued Ideation}

Foa (1979) noted that, unlike most obsessive-compulsives who recognize that their feared situations are in fact harmless, those who believe that their fears are realistic and their rituals jusified show a decrease in self-reported fear within sessions, but not across sessions. This resistance to change in the face of repeated exposures may occur because the structure of the belief prevents realization of corrective information and/or because the available information is misinterpreted. "Overvalued ideators" often develop elaborate scenarios involving long-term consequences, thus precluding their ready disconfirmation during the course of therapy, such as, "Visiting a hospital will result in cancer development sometime within the next thirty years." In addition, a patient's "theory" of potential harm may be so prolific with qualifications (like many Ptolemaic epicycles) that new information is readily accommodated and disconfirmation is difficult to achieve. Thus, fear persists in overvalued ideators because their beliefs about harm are especially robust or because the protean ramifications of their beliefs defy disconfirmation.

The persistence of erroneous evaluations and interpretations in the face of corrective information might also be mediated by impairments in rules of inference. Basic epistemological errors such as affirmation of entities simply because their existence is not disproven and failure to make appropriate inductive generalizations from specific situations could mitigate the effects of fear-relevant evidence. For example, for a germ phobic the absence of evidence that leukemia is contagious is not grounds for comfort. Rather, it is taken as supportive of the hypothesis of contagion! Furthermore, for many phobics, multiple safe encounters with a feared situation fail to constitute inductive evidence for future safety. Repeated imaginal exposure to harmful events (e.g., catching leukemia) effects improvement via habituation, which reduces the negative valance associated with the feared harm. The probability of harm represented in such fear structures, however, remains unchanged.

\section{Theoretical and Practical Implications}

We have offered an account for the mechanisms by which exposure to feared situations reduces fear through the integration of information embedded therein. Furthermore, the kind of information that is necessary and sufficient for correction of the fear memory has been proposed. How does our account of emotional processing go beyond alternative views?

Traditional stimulus-response (S-R) theories explain fear reduction by the presentation of the conditioned stimulus (CS) complex in the absence of the unconditioned stimulus (UCS), that is, by extinction. This view focuses on only one kind of information, CS-UCS relations, to account for fear reduction. Although changes in CS-UCS relations can be construed as modifying probability representations, we have argued that changes in probability constitute only one way to modify fear structures. The two additional mechanisms for fear reduction proposed here, physiological habituation and changes in valence, are not accommodated by traditional $\mathrm{S}-\mathrm{R}$ theories. Consequently, these theories cannot account for certain clinical observations. For example, the concept of impaired physiological habituation is required to account for cases in which fear is evoked during prolonged exposure, but the expected fear reduction does not occur. The concept of valence is necessary to explain why fear reduction occurs despite imaginal exposure to feared consequences, that is, to the CS-UCS contingency.

More generally, S-R explanations of fear acquisition and ex- 
tinction involve a level of theorizing that cannot accommodate the higher order abstractions of threat and danger, which in our view are essential to integrate fear phenomena. Following Fodor's (1968) argument for the necessity of psychological explanations in terms of abstract functional states, Kozak and Miller (1982) suggested that fear should be construed as a state that is recognized "by some supposed common meaning or interpretation of varied response patterns in varied situations" (p. 356). In the present theory, the representation of threat or danger constitutes this common meaning, and thus, in part defines a fear structure. Contemporary learning theorists (e.g., Rescorla, 1978; Wagner, 1978) do address issues that are relevant to meaning, such as the phenomena of expectancies, priming, and blocking by evoking S-S explanations. However, as with S-R concepts, S-S explanations also involve a level of theorizing that cannot accommodate the abstract concepts of threat and danger.

Several cognitive theories (e.g., Beck, Emery, \& Greenberg, 1985) do focus on illogical and erroneous ideas of threat, as does the present formulation. They cannot, however, account for clinical observations such as the relations found among long- versus short-term habituation, fear ideation, and treatment outcome. With the possible exception of Stampfl and Levis's (1967) account of fear reduction, neither S-R nor cognitive approaches explain the relation between physiological activation during exposure and treatment outcome. This phenomenon is explained by the bioinformational theory (Lang, 1977, 1979), which does not, however, address the connection between fear and erroneous ideas. Thus, for example, bioinformational theory does not explain how mistaken ideas can underlie the persistence of fear in overvalued ideators. Our hypothesis that evaluative information about the likelihood of harm can be represented as meaning elements of a fear structure seems to go beyond Lang's (1979, p. 502) idea that meaning elements consist of semantic information (e.g., "snakes are dangerous!"). The concept of meaning advanced here involves the representation of interrelations among stimuli and responses that are not necessarily semantically coded. Probability information is often embedded in such relations. For example, the danger of a red light is represented by its association with shock; this association includes probability information that reflects learning history.

The proposed framework integrates a large body of findings and may constitute a heuristic for the further study of emotional processing. For anxiety, several foci of investigation emerge: (a) the specific pathology of the information structures of different neurotic fears, (b) the kind of information needed to correct neurotic fear structures, and (c) the delivery procedures that best promote incorporation of corrective information. On the basis of clinical observations, outcome of therapy literature, and the formal descriptions of Diagnostic and Statistical Manual: III (DSM-III; American Psychiatric Association, 1980), we have hypothesized elsewhere (Foa \& Kozak, 1985) that neurotic fear structures are distinguished by erroneous representations of threat, high negative valence for a threatening event, and/or excessive response elements (e.g., physiological avoidance, etc.). In addition, neurotic fear structures are characterized by their resistance to modification. Research should therefore be directed not only at exploring hypotheses about the characteristics of fear structures in general, but also at identifying characteristics specific to particular anxiety disorders. This exploration can illuminate deficits or impairments in the mechanisms of fear reduction that have been postulated here.

The proposed framework yields several hypotheses about the persistence of neurotic fear. Persistence in the face of exposure may reflect failure to access the fear structure either because of active avoidance or because the idiosyncratic content of the structure precludes spontaneous encounters with evocative situations in everyday life (e.g., as in fear of contamination by funeral homes). Alternatively, fear may persist despite such encounters because of some impairment in the mechanism of change. Cognitive defenses, excessive arousal with failure to habituate, faulty premises, and erroneous rules of inference merit investigation as possible impairments that would hinder emotional processing.

Hypotheses about psychopathology that are derived from the present account of emotional processing offer guidance for the treatment of anxiety. Accordingly, a fundamental task of any therapy for fear is to identify the events that evoke it and to formulate potent methods to institute corrective information. Fear evocation during therapy indicates the availability of the fear structure for modification. Knowledge of conditions that enhance fear evocation is thus pertinent to treatment. We have already discussed several such conditions, such as attention, evocative medium, and structural matching. Also of potential import is the relation between mood state and accessing. Indeed, memories that have been learned in a certain affective state were found to be more readily evoked in that state (cf. Bower, 1981; Teasdale, 1983). Furthermore, a congruency between memory content and the mood in which it is accessed was found to facilitate remembering (cf. Teasdale, 1983). Therefore, to the extent that a mood state influences accessing, it would be expected to influence emotional processing.

Information needed for fear reduction and the optimal conditions for its realization will vary with specific fear structures as well as with specific impairments in the mechanisms underlying fear reduction. For instance, when extreme physiological activity is an impairment, it is expected that procedures promoting habituation will be required; when distorted evaluations of external threat predominate, analysis of the erroneous beliefs should be undertaken to reach a decision about optimal intervention. For example, it is conceivable that representations of the probability of negative consequences are best modified through in vivo exposure. Valence, on the other hand, may be more influenced through imaginal procedures because disastrous consequences can be realized, and consequently habituated to, only in the imagination.

As we discussed earlier, imaginal exposure has fallen out of favor and in vivo exposure has become the treatment of choice for anxiety reduction (e.g., Emmelkamp, 1982; Marks, 1978). Nevertheless, a categorical preference for any one medium belies the complexity of the relation between the fear structure and the therapeutic situation. Given an optimal match between the two, in vivo exposure may best evoke fear. However, imaginal procedures may provide greater flexibility in approaching an optimal match. For the relatively less complicated structure of simple phobias, it may be a simple matter to create an in vivo situation that is sufficiently similar to the fear memory to evoke it. Accessing more complex structures, such as those of social fears, may require the greater flexibility allowed by an imaginal pro- 
cedure. Although the literature on the relative efficacy of different media for different anxiety disorders is strongly suggestive, our conclusions are limited because the data are culled from individual experiments not designed to examine the interactive effects of media and disorder on activation, habituation, and outcome. For stronger conclusions, such designs are needed.

In the present article we have focused on understanding emotional processing of fear via behavioral treatment. In comparison to fear, fewer hypotheses have been advanced in the literature about structures for sadness, anger, and other colloquially described emotions. Nevertheless, the reported success of imaginal confrontation with a lost love-object in reducing unresolved grief (Ramsay, 1977), as well as Novaco's (1975) program for controlling anger, might be understood through analyses of the relevant information structures. It is possible, then, that the concept of emotional processing offered here will not be limited to the study of fear, but will also provide a model for the study of other emotions, their pathology, and their modification.

\section{References}

Abramson, L. Y., Seligman, M.E.P., \& Teasdale, J. D. (1978). Learned helplessness in humans: Critique and reformulation. Journal of $A b$ normal Psychology, 87, 49-74.

American Psychiatric Association (1980). Diagnostic and statistical manual of mental disorders (3rd ed.). Washington, DC: Author.

Anderson, (1976). Language, memory, and thought. Hillsdale, NJ: Erlbaum.

Anderson, M. P., \& Borkovec, T. D. (1980). Imagery processing and fear reduction during repeated exposure to two types of phobic imagery. Behaviour Research and Therapy, 18, 537-540.

Anderson, J. R., \& Bower, G. H. (1973). Human associative memory. Washington, DC: V. H. Winston \& Sons.

Anderson, J. R., \& Bower, G. H. (1974). A propositional theory of recognition memory. Memory and cognition, 2, 406-412.

Bandura, A. (1977). Self-efficacy: Toward a unifying theory of behavioral change. Psychological Review, 84, 191-215.

Bandura, A., Blanchard, E. B., \& Ritter, B. (1969). Relative efficacy of desensitization and modeling approaches for inducing behavioral, affective, and attitudinal changes. Journal of Personality and Social Psychology, 13, 173-199.

Bandura, A., Grusec, J. E., and Menlove, F. L. (1967). Vicarious extinction of avoidance behavior. Journal of Personality and Social Psychology, $5,449-455$.

Barber, T. X., \& Hahn, K. W. (1964). Experimental studies in "hypnotic" behavior: Physiologic and subjective effects of imagined pain. Journal of Nervous and Mental Disease, 139, 416-425.

Barlow, D. H., Leitenberg, H., Agras, W. S., \& Wincze, J. P. (1969). The transfer gap in systematic desensitization: An analogue study. Behavior Research and Therapy, 7, 191-196.

Beck, A. T., Emery, G., \& Greenberg, R. L. (1985). Anxiety disorders and phobias, New York: Basic Books.

Benjamin, S., Marks, I. M., \& Huson, J. (1972). Active muscular relaxation in desensitization of phobic patients. Psychological Medicine, 2, 381390.

Borkovec, T. D., \& Grayson, J. B. (1980). Consequences of increasing the functional impact of internal emotional stimuli. In K. Blankstein, P. Pliner, \& L. H. Polivey (Eds.), Advances in the study of communication and affects (Vol. 3, pp. 117-137). New York: Plenum Press.

Borkovec, T. D., \& Sides, J. (1979). The contribution of relaxation and expectance to fear reduction via graded imaginal exposure to feared stimuli. Behaviour Research and Therapy, 17, 529-540.

Boulougouris, J. C. (1977). Variables affecting the behavior modification of obsessive-compulsive patients treated by flooding. In J. C. Boulougouris \& A. D. Rabavilas (Eds.), The treatment of phobic and obsessivecompulsive disorders (pp. 73-84). New York: Pergamon Press.

Bower, G. H. (1981). Mood and memory. American Psychologist, 36, 129-148.

Bradley, B., \& Mathews, A. (1983). Negative self-schemata in clinical depression. British Journal of Clinical Psychology, 22, 173-181.

Bugelski, B. R. (1970). Words and things and images. American Psychologist, 25, 1002-1012.

Butler, G, \& Matthews, A. (1983). Cognitive processes in anxiety. Advances in Behavior Research and Therapy, 5, 51-62.

Chambless, D. L., Foa, E. B., Groves, G. A., \& Goldstein, A. J. (1980). Flooding with Brevital in the treatment of agoraphobia: Countereffective? Behaviour Research and Therapy, 17, 243-25I.

Chambless, D. L., Foa, E. B., Groves, G. A., \& Goldstein, A. J. (1982). Exposure and communications training in the treatment of agoraphobia. Behaviour Research and Therapy, 20, 219-231.

Chaplin, E. W., \& Levine, B. A. (1980). The effects of total exposure duration and interrupted versus continuous exposure in flooding. $B e$ havior Therapy, 12, 360-368.

Craig, K. G. (1968). Physiological arousal as a function of imagined, vicarious, and direct stress experiences. Journal of Abnormal Psychology, 73, 513-520.

Davis, M., \& Wagner, A. R. (1969). Habituation of the startle response under incremental sequence of stimulus intensities. Journal of Comparative and Physiological Psychology, 67, 486-492.

DeSilva, P., \& Rachman, S. (1982). Is exposure a necessary condition for fear reduction? Behaviour Research and Therapy, 19, 227-232.

Dyckman, J. M., \& Cowan, P. A. (1978). Imagining vividness and the outcome of in vivo and imagined scene desensitization. Journal of Consulting and Clinical Psychology, 48, 1155-1156.

Emmelkamp, P. M. G. (1982). In vivo treatment of agoraphobia. In D. L. Chambless \& A. J. Goldstein (Eds.), Agoraphobia (pp. 43-75). New York: Wiley.

Emmelkamp, P. M. G., \& Kuipers, A. C. M. (1979). Agoraphobia: A follow-up study four years after treatment. British Journal of Psychiatry, I34, 352-355.

Emmelkamp, P. M. G., \& Wessels, H. (1975). Flooding in imagination v. flooding in vivo. A comparison with agoraphobics. Behaviour Research and Therapy, 13, 7-15.

Eysenck, H. J. (1976). The learning theory model of neurosis-A new approach. Behaviour Research and Therapy, 14, 251-267.

Fenichel, O. (1963). The psychoanalytic theory of neurosis. London: Routledge \& Kegan.

Foa, E. B. (1979). Failure in treating obsessive-compulsives. Behaviour Research and Therapy, 16, 391-399.

Foa, E. B., \& Chambless, D. L. (1978). Habituation of subjective anxiety during flooding in imagery. Behaviour Research and Therapy, 16, $391-$ 399.

Foa, E. B., \& Emmelkamp, P. M. G. (1983). Failures in behavior therapy. New York: Wiley.

Foa, E. B., Grayson, J. B., Steketee, G. S., Doppelt, H. G., Turner, R. M., \& Latimer, P. R. (1983). Success and failure in the behavioral treatment of obsessive-compulsives. Journal of Consulting and Clinical Psychology, 51, 287-297.

Foa, E. B., \& Kozak, M. J. (1985). Treatment of anxiety disorders: Implications for psychopathology. In A. H. Tuma \& J. D. Maser (Eds.), Anxiety and the anxiety disorders (pp. 451-452). Hillsdale, NJ: Erlbaum.

Foa, E. B., Steketee, G., \& Grayson, J. B. (1985). Imaginal and in vivo exposure: A comparison with obsessive-compulsive checkers. Behavior Therapy, 16, 292-302.

Foa, E. B., Steketee, G. S., Turner, R. M., \& Fischer, S. C. (1980). Effects of imaginal exposure to feared disasters in obsessive-compulsive checkers. Behaviour Research and Therapy, 18, 449-455. 
Fodor, J. (1968). Psychological explanation. New York: Random House. Freud, S. (1956). Turnings in the ways of psychoanalytic therapy. In E. Jones (Ed.), Collected papers (Vol. 2, pp. 392-402). London, Hogarth Press.

Gatchel, R. J., \& Proctor, J. D. (1976). Physiological correlates of learned helplessness in man. Journal of Abnormal Psychology, 85, 27-34.

Grayson, J. B. (1982). The elicitation and habituation of orienting and defensive responses to phobic imagery and the incremental stimulus intensity effect. Psychophysiology, 19, 104-111.

Grayson, J. B., Foa, E. B., \& Steketee, G. (1982). Habituation during exposure treatment: Distraction versus attention-focusing. Behaviour Research and Therapy, 20, 323-328.

Greenfield, N. S., Katz, D., Alexander, A. A., \& Roessler, R. (1963). The relationship between physiological and psychological responsivity: Depression and galvanic skin response. Journal of Nervous and Mental Disease, 136, 535-539.

Grings, W. W. (1976). Inhibition in autonomic conditioning. In D. I. Mostofsky (Ed.), Behavior control and modification of physiological activity (pp. 286-296). Englewood Cliffs, NJ: Prentice-Hall.

Grossberg, J. M., \& Wilson, H. K. (1968). Physiological changes accompanying the visualization of fearful and neutral situations. Journal of Personality and Social Psychölogy, 10, 124-133.

Groves, P. M., \& Lynch, G. S. (1972). Mechanisms of habituation in the brain stem. Psychological Review, 79, 237-244.

Groves, P. M., \& Thompson, R. F. (1970). Habituation: A dual-process theory. Psychological Review, 77, 429-450.

Gur, R. C., Reivich, M., Rosen, A. D., Alavi, A., Greenberg, J., \& Gur, R. E. (1981, February). Anxiety and local glucose metabolism in frontocortical limbic projections in man. Paper presented at the meeting of the International Neuropsychological Society, Atlanta, GA.

Hafner, R. J., \& Marks, I. M. (1976). Exposure in vivo of agoraphobics: Contributions of diazepam, group exposure, and anxiety evocation. Psychological Medicine, 6, 71-88.

Hart, J. D. (1966). Fear reduction as a function of the assumption and success of a therapeutic role. Unpublished master's thesis, University of Wisconsin, Madison.

Hayes-Roth, B. (1977). Evolution of cognitive structures and processes. Psychological Review, 84, 260-278.

Jacobson, E. (1930). Electrical measurements of neuromuscular states during mental activities: I. Imagination of movement involving skeletal muscle. American Journal of Physiology, 91, 567-608.

Kahneman, D., \& Tversky, A. (1982). On the study of statistical intuitions. Cognition, 11, 123-141.

Kazdin, A. E. (1973). Covert modeling and the reduction of avoidance behavior. Journal of Abnormal Psychology, 81, 87-95.

Kazdin, A. E. (1974a). Covert modeling, model similarity, and reduction of avoidance behavior. Behavior Therapy, 5, 325-340.

Kazdin, A. E. (1974b). The effect of model identity and fear-relevant similarity on covert modeling. Behavior Therapy, 5, 624-635.

Kamin, L. J. (1969). Predictability, surprise, attention, and conditioning. In B. A. Campbell \& R. M. Church (Eds.), Punishment and aversive behavior (pp. 279-296). New York: Appleton-Century-Crofts.

Kieras, D. (1978). Beyond pictures and words: Alternate information processing models for imagery effects in verbal memory. Psychological Bulletin, 85, 532-554.

Kintsch, W. (1972). Notes on the structure of semantic memory. In E. Tulving \& W. Donaldson (Eds.), Organization of memory (pp. 249308). New York: Academic Press.

Kosslyn, S. M. (1980). Image and mind. Cambridge, MA: Harvard University Press.

Kozak, M. J. (1982). The psychophysiological effects of training on variously elicited imaginings. Unpublished doctoral dissertation, University of Wisconsin, Madison.

Kozak, M. J., \& Miller, G. A. (1982). Hypothetical constructs vs. intervening variables: A reappraisal of three-systems anxiety assessment. Behavioral Assessment, 4, 347-358.
Lader, M. H., Gelder, M. G., \& Marks, I. M. (1967). Palmar skin conductance measures of predictions of response to desensitization. Journal of Psychosomatic Research, 11, 283-290.

Lader, M. H., \& Mathews, A. M. (1968). A physiological model of phobic anxiety and desensitization. Behaviour Research and Therapy, 6, 411421.

Lader, M. H., \& Wing, L. (1966). Physiological measures, sedative drugs, and morbid anxiety. London: Oxford University Press.

Lader, M. H., \& Wing, L. (1969). Physiological measures in agitated and retarded depressed patients. Journal of Psychiatric Research, 7, 89100.

Lang, P. J. (1968). Fear reduction and fear behavior. Problems in treating a construct. In J. M. Shlien (Ed.), Research in psychotherapy (Vol. 3, pp. 90-102). Washington, DC: American Psychological Association.

Lang, P. J. (1977). Imagery in therapy: An information processing analysis of fear. Behavior Therapy, 8, 862-886.

Lang, P. J. (1979). A bio-informational theory of emotional imagery. Psychophysiology, 16, 495-512.

Lang, P. J., Kozak, M. J., Miller, G. A., Levin, D. N., \& McLean, A. (1980). Emotional imagery: Conceptual structure and pattern of somatic-visceral response. Psychophysiology, 17, 179-192.

Lang, P. J., Levin, D. N., Miller, G. A., \& Kozak, M. J. (1983). Fear behavior, fear imagery, and the psychophysiology of emotion: The problem of affective response integration. Journal of Abnormal Psychology, 92, 276-306.

Lang, P. J., Melamed, B. G., \& Hart, J. (1970). A psychophysiological analysis of fear modification using an automated desensitization procedure. Journal of Abnormal Psychology, 76, 220-234.

Levey, A. B., \& Martin, I. (1983). Cognitions, evaluations and conditioning: Rules of sequence and rules of consequence. Advances in Behaviour Research and Therapy, 4, 177-195.

Levin, D. N. (1982). The psychophysiology of fear reduction: Role of response activation during emotional imagery. Unpublished doctoral dissertation, University of Wisconsin, Madison.

Levin, D. N., Cook, E. W., III, \& Lang, P. J. (1982). Fear imagery and fear behavior: Psychophysiological analysis of clients receiving treatment for anxiety disorders. Psychophysiology, 19, 571-572.

Lewinsohn, P. M., Lobits, W. C., \& Wilson, S. (1973). "Sensitivity" of depressed individuals to aversive stimuli. Journal of Abnormal $P_{s y-}$ chology, 81, 259-263.

LoPiccolo, J. (1969). Effective components of systematic desensitization. Unpublished doctoral dissertation, Yale University, New Haven.

Marks, I. M. (1978). Behavioral psychotherapy of adult neurosis. In S. L. Garfield \& A. E. Bergin (Eds.), Handbook of psychotherapy and behavior change (2nd ed., pp. 493-589). New York: Wiley.

Marks, l. M., Hodgson, R., \& Rachman, S. (1975). Treatment of chronic obsessive-compulsive neurosis by in vivo exposure. British Journal of Psychiatry, 127, 349-364.

Marks, I. M., Stern, R. S., Mawson, D., Cobb, J., \& McDonald, R. (1980). Clomipramine and exposure for obsessive-compulsive rituals: I. British Journal of Psychiatry, 136, 1-25.

Mathews, A. M. (1978). Fear-reduction research and clinical phobias. Psychological Bulletin, 85, 390-404.

Mathews, A. M., Johnston, D. W., Lancashire, M., Munby, D., Shaw, P. M., \& Gelder, M. G. (1976). Imaginal flooding and exposure to real phobic situations: Treatment outcome with agoraphobic patients. British Journal of Psychiatry, 129, 362-371.

Mathews, A. M., \& Shaw, P. (1973). Emotional arousal and persuasion effects in flooding. Behaviour Research and Therapy, 11, 587-598.

May, J. R. (1977). A psychophysiological study of self and externally regulated phobic thoughts. Behavior Therapy, 8, 849-861.

McCutcheon, B. A., \& Adams, H. E. (1975). The physiological basis of implosive therapy. Behaviour Research and Therapy, 13, 93-100.

McLean, A., Jr. (1981). Emotional imagery: Stimulus information, imagery ability, and patterns of physiological response. Unpublished doctoral dissertation, University of Wisconsin, Madison. 
Miller, G. A., Levin, D. N., Kozak, M. J., Cook, E. W., McLean, A., Carroll, J., \& Lang, P. J. (1981). Emotional imagery: Individual differences in imagery ability and physiological response. Psychophysiology, 18, 196.

Mowrer, O. H. (1960). Learning theory and behavior. New York: Wiley.

Nisbett, R. E., \& Wilson, T. P. (1977). Telling more than we know: Verbal reports on mental processes. Psychological Review, 84, 231-279.

Novaco, R. W. (1975), Anger control: The development and evaluation of an experimental treatment. Lexington, MA: Heath.

Nunes, J. S., \& Marks, I. M. (1975). Feedback of true heart rate during exposure in vivo. Archives of General Psychiatry, 32, 933-936.

O'Gorman, J., \& Jamieson, R. (1975). The incremental stimulus intensity effect and habituation of autonomic responses in man. Physiological Psychology, 3, 385-389.

Ornstein, H., \& Carr, J. (1975). Implosion therapy by tape-recording. Behaviour Research and Therapy, 13, 177-182.

Paivio, A. (1971) Imagery and verbal processes. New York: Holt, Rinehart \& Winston.

Perls, F. S. (1969). Gestall therapy verbatim. Moab, UT: Real People Press.

Pylyshyn, Z. W. (1973). What the mind's eye tells the mind's brain: A critique of mental imagery. Psychological Bulletin, 80, 1-22.

Rabavilas, A. D., Boulougouris, J. C., \& Stefanis, C. (1976). Duration of flooding sessions in the treatment of obsessive-compulsive patients. Behaviour Research and Therapy, 14, 349-355.

Rachman, S. (1980). Emotional processing. Behaviour Research and Therapy, 18, 51-60.

Rachman, S. (1976). The passing of the two stage theory of fear and avoidance: Fresh possibilities. Behaviour Research and Therapy, 14, $125-132$.

Ramsay, R. W. (1977) Behavioral approaches to bereavement. Behaviour Research and Therapy, 15, 131-136.

Reiss, S. (1980). Pavlovian conditioning and human fear: An expectancy model. Behavior Therapy, 11, 380-396.

Rescorla, R. A. (1978). Some implications of a cognitive perspective on Pavlovian conditioning. In S. H. Hulse, H. Fowler, \& W. K. Honig (Eds.). Cognitive processes in animal behavior (pp. 15-50). Hillsdale, NJ: Erlbaum.

Rimm, D. C., Janda, L. H., Lancaster, D. W., Nahl, M., \& Dittmar, K. (1977). An exploratory investigation of the origin and maintenance of phobias. Behaviour Research and Therapy, 15, 231-238.

Sartory, G., Rachman, S., \& Grey, S. J. (1982). Return of fear: The role of rehearsal. Behaviour Research and Therapy, 20, 123-133.

Seligman, M.E.P.(1975). Helplessness: On depression, development and death. San Francisco: Freeman.

Shahar, A., \& Marks, I. M. (1980). Habituation during exposure treatment of compulsive rituals. Behavior Therapy, 11, 397-401.

Shaw, W. A. (1940). The distribution of muscular action potentials to imaginal weight lifting. Archives of Psychology, 247, 1-50.
Sherman, A. R. (1972). Real life exposure as a primary therapeutic factor in desensitization treatment of fear. Journal of Abnormal Psychology, $79,19-28$.

Sorgatz, H., \& Frumm, N. (1978). Feeling of improvement in flooding: Some analogue data. Psychological Reports, 42, 1187-1191.

Stampfl, T. G., \& Levis, D. J. (1967). Essentials of implosive therapy: A learning-theory-based psychodynamic behavioral therapy. Journal of Abnormal Psychology, 72, 496-503.

Stern, R., \& Marks, l. M. (1973). Brief and prolonged flooding: A comparison in agoraphobic patients. Archives of General Psychiatry, 28, 270-276.

Teasdale, T. D. (1983). Negative thinking in depression: Cause, effect, or reciprocal relationship? Advances in Behavior Research and Therapy, 5, 3-25.

Thompson, R. F., \& Spencer, W. A. (1966). Habituation: A model phenomenon for the study of neuronal substrates of behavior. Psychological Review, 73, 16-43.

Tighe, T. J., \& Leaton, R. N. (Eds.). (1976). Habituation: perspectives from child development, animal behavior and neurophysiology. Hillsdale, NJ: Erlbaum.

Van Den Berg, O., \& Eelen, P. (1985) Unconscious processing and emotions. Unpublished manuscript, University of Leuven, Dept. of Psychology, Belgium.

Wagner, A. R. (1978). Expectancies and priming of STM. In S. H. Hulse, H. Fowler, \& W. K. Honig (Eds.), Cognitive processes in animal behavior (pp. 177-209). Hillside, NJ: Erlbaum. 177-209.

Wagner, A. R., \& Rescorla, R. A. (1972). Inhibition in Pavlovian conditioning: Applications of a theory. In R. A. Boakes \& M. S. Halliday (Eds.), Inhibition and learning (pp. 301-336). New York: Academic Press.

Watson, J. P., Gaind, R., \& Marks, I. M. (1972). Physiological habituation to continuous phobic stimulation. Behaviour Research and Therapy, $10,269-278$.

Watson, J. P., \& Marks, I. M. (1971). Relevant and irrelevant fear in flooding-A crossover study of phobic patients. Behavior Therapy, 2, 275-293.

Watts, F. N. (1979). Habituation model of systematic desensitization. Psychological Bulletin, 86, 627-637.

Weerts, T. C. (1973). Physiological specificity in cognitive functioning. Unpublished doctorial dissertation, University of Wisconsin, Madison.

Yerkes, R. M., \& Dodson, J. D. (1908). The relation of strength of stimulus to rapidity of habit-formation. Journal of Comparative Neurology, 18, 459-482.

Zitrin, C. M., Klein, D. F., \& Woerner, M. G. (1980). Treatment of agoraphobia with group exposure in vivo and imipramine. Archives of General Psychiatry, 37, 63-72.

Received April 12, 1985

Revision received August 5, 1985 